\title{
Comparison of Two Insemination Programs in Synchronized Early Postpartum Zebu Cows under Tropical Conditions: An Economic Appraisal
}

\author{
Adalinda Hernández ${ }^{1}$, Carlos Salvador Galina ${ }^{1 *}$, Ramiro Diaz ${ }^{1}$, Ivette Rubio², \\ Manuel Corro' ${ }^{2}$, Juan José Romero ${ }^{3}$ \\ ${ }^{1}$ Departamento de Reproducción, Facultad de Medicina Veterinaria y Zootecnia, Universidad Nacional \\ Autónoma de México, Mexico City, México \\ ${ }^{2}$ Centro de Enseñanza Investigación y Extensión en Ganadería Tropical, Facultad de Medicina Veterinaria y \\ Zootecnia, Universidad Nacional Autónoma de México, Tlapacoyan, México \\ ${ }^{3}$ Escuela de Medicina Veterinaria, Universidad Nacional, Heredia, Costa Rica \\ Email: "cgalina@servidor.unam.mx
}

Received 24 September 2015; accepted 6 December 2015; published 11 December 2015

Copyright (C) 2015 by authors and Scientific Research Publishing Inc.

This work is licensed under the Creative Commons Attribution International License (CC BY). http://creativecommons.org/licenses/by/4.0/

c) (i) Open Access

\section{Abstract}

To evaluate an artificial insemination program in postpartum Bos indicus cows and by using deterministic models, to estimate the possible economic advantages of insemination by appointment over detected estrus, sixty-three multiparous animals were synchronized using a progestagen device inserted at day 31 and withdrawn after 9 days (average time for withdrawal was $40.9 \pm 6.8$ days). Cows were observed continuously from 0700 to 1800 during $72 \mathrm{~h}$. The percentage of animals detected positive to estrus by riding behavior was $43.4 \%$, transrectal palpation, $22 \%$ and heat detector patches, $4.6 \%$. The percentage of cows ovulating as evidenced by progesterone samples taken at 9 and 11 days after the average estrus response was $73 \%$. The economical assessment by using the values obtained in the present study afforded that the cost of semen, ovulation rate and fertility point to a definitive advantage of using $\mathrm{AI}$ at fixed time over a program based on estrus detection.

\section{Keywords}

Insemination, Estrus Detection, Behavior, Bos indicus

\footnotetext{
${ }^{*}$ Corresponding author.
}

How to cite this paper: Hernández, A., Galina, C.S., Diaz, R., Rubio, I., Corro, M. and Romero, J.J. (2015) Comparison of Two Insemination Programs in Synchronized Early Postpartum Zebu Cows under Tropical Conditions: An Economic Appraisal. Open Journal of Veterinary Medicine, 5, 234-242. http://dx.doi.org/10.4236/ojvm.2015.512032 


\section{Introduction}

There have been several efforts to evaluate the economical impact of the use of AI, especially in Holstein cows raised under intensive systems where insemination following estrus detection (AIED) or at fixed time (AIFT) are common procedures [1] [2]. However, the difficulties in estrus detection in beef cattle has forced technologists to use the latter method to eliminate the need for detecting overt signs of estrus facilitating management during the postpartum period in beef cattle raised under semi or extensive pastoral systems in the tropics [3]-[5]. On the other hand, scarce efforts have been vested to assess the economical feasibility of using either method (AIED vs. AIFT) in beef cows. For example, Rodgers et al. [6] compared the efficacy inseminating at fixed time versus natural mating with the weight of the calves at weaning finding an economical advantage in the former method. This is particularly important in postpartum beef cows in the tropics where the response can be misleading as the development of a corpus luteum (CL) following induced estrus, and has afforded doubts to whether this technique is viable at least under tropical conditions. Effectively, Díaz et al. [7] and later PérezTorres et al. [8] found that almost 30\% of the animals could display behavioral estrus while not ovulating, as shown by serum progesterone values indicative of the formation of a mature CL. Moreover, fertility results following AI by appointment are inconsistent. For example, Alonso-Alanuza et al. [9] in a field trial evaluating fixed $\mathrm{AI}$ at 48 and $72 \mathrm{~h}$ but observing cows continuously for overt signs of estrus found that eighty-six percent of the pregnancies occurred in cows displaying estrous behavior regardless of the time of fixed AI versus applying this technique by appointment.

With this in mind, the objective of the present study was to undertake a field trial to estimate the physiological values on estrus detection efficacy, the formation of a CL indicative of ovulation and the use of external aids to increase the number of animals detected in estrus, in order to assess the convenience of inseminating post partum Bos indicus cows at observed estrus and the data compared with the hypothetical use of AI at fixed time using a modeling procedure to assess the economical value of both procedures.

\section{Material and Methods}

\subsection{Ethical Statement}

The methods used during the present work were approved by the Animal Care Internal Committee (CICUA) of the Faculty of Veterinary Medicine and Zootechnics of the National Autonomous University of Mexico in accordance to The Code of Ethics of the World Medical Association (Declaration of Helsinki).

\subsection{Location}

The study was carried out at the Centre for Teaching, Research and Extension in Tropical Animal Husbandry of the Faculty of Veterinary Medicine of the National Autonomous University of Mexico, located in the state of Veracruz, Mexico at $20^{\circ} 4^{\prime} \mathrm{N}$ and $97^{\circ} 3^{\prime} \mathrm{W}$. The climate is hot and humid, without a defined dry season. Average yearly rainfall is $1840 \mathrm{~mm}$ and average temperature range between $14^{\circ} \mathrm{C}$ and $35^{\circ} \mathrm{C}$. The animals were at pasture at all times, with two or three days of grazing, 50 to 70 days of recovery, stocking rate of 1.25 animal units [AU $=450 \mathrm{~kg}$ of live weight]/ha). The pasture was composed of an average of $39 \%$ of introduced grasses, mainly Stargrass (Cynodon nlemfuensis); 48\% for native grasses, mainly Paspalum spp. and Axonopus spp.; 3\% for broad-leafed weeds; 6\% for narrow-leafed weeds and 5\% for native legumes, mainly Desmodium spp. Mineralized salt was offered ad libitum.

\subsection{Animals and Sampling Procedures}

In order to have all animals as close as possible to 35 days postpartum in a calving season of about 60 days, a total of 63 cows with a body condition score of 3 to 4 on a scale of 1 - 5 [10]. Cows were allotted to five groups which were formed as they reached the target date. The study was undertaken in the months of May and June 2014 (average temp 24.9 and humidity 95.7\%). A progesterone releasing device (CIDR ${ }^{\circledR}$ Zoetis Mexico) was inserted at day 31 and withdrawn after 9 days (average time for withdrawal of the device was $40.9 \pm 6.8$ days for all groups) according to the procedure previously described [8] (Table 1). The five groups of cows remained together throughout the study. The resumption of ovarian activity was evaluated by measuring the concentrations of progesterone on days 21 and 26 postpartum to assess the presence of ovarian activity prior to treatment. 
Table 1. Frequencies of cows in the five groups displaying visible estrous behavior, as opposed detection by transrectal palpation at $56 \mathrm{~h}$ after CIDR withdrawal or animals non visible in estrus.

\begin{tabular}{cccccccccc}
\hline \multirow{2}{*}{ Group } & $\mathbf{n}=$ & $\begin{array}{c}\text { Interval of days from } \\
\text { calving to CIDR removal }\end{array}$ & Visible & Palpation & Non visible & Visible & Doubtful & Negative \\
\cline { 6 - 9 } & & $44.5 \pm 8.3$ & 18 & 27 & 55 & 0 & 0 & 100 \\
$\mathbf{1}$ & 11 & $43.9 \pm 3.0$ & 45 & 36 & 18 & 9 & 9 & 82 \\
$\mathbf{2}$ & 11 & $34.2 \pm 4.5$ & 46 & 31 & 23 & 8 & 0 & 92 \\
$\mathbf{3}$ & 13 & $41.4 \pm 6.2$ & 38 & 15 & 46 & 0 & 23 & 77 \\
$\mathbf{4}$ & 13 & $40.7 \pm 12.1$ & 69 & 0 & 31 & 6 & 6 & 88 \\
$\mathbf{5}$ & 15 & $\mathbf{4 0 . 9}$ & $\mathbf{6 . 8}$ & $\mathbf{4 3 . 4 \%}$ & $\mathbf{2 2 . 0 \%}$ & $\mathbf{3 4 . 6 \%}$ & $\mathbf{4 . 6 \%}$ & $\mathbf{7 . 7 \%}$ & $\mathbf{8 7 . 7 \%}$ \\
\hline
\end{tabular}

Three days after CIDR removal, blood samples were taken at day 9 and 11 to verify the presence of a corpus luteum at the time when overt signs of estrus would be expected to appear. The samples were handled according to the recommendations of Pulido et al. [11] and centrifuged at $1500 \mathrm{rpm}$ for 10 minutes and kept frozen according to the procedure previously described [8]. Serum was analyzed using a solid phase radioimmunoassay in $100 \mu \mathrm{l}$ of serum using commercial kits (Pharmaceuticals, Diagnostic Division). The intra and inter-assay coefficients of variation were $7.41 \%$ and $6.18 \%$, respectively. When the concentration of progesterone was above 0.5 $\mathrm{ng} / \mathrm{ml}$ in two or more successive samples, the animal was considered to have a functional corpus luteum [11].

\subsection{Observations for Signs of Estrus}

Cows were observed continuously immediately after implant withdrawal. The period of observation extended from 0700 to 1800 for $72 \mathrm{~h}$. Signs of estrus were classified according to the following criteria: a) showing overt signs: sexual behaviors (e.g. mounting and intent to mount) and courtship [12] [13] including head bumping flehmen, sniffing, following, licking and assisted head resting [14]; b) transrectal palpation: cows which did not display overt signs were detected in estrus by transrectal palpation at 56 hours by gently massaging the uterus per rectum and observing the presence of mucous discharge or a wet and congested vulva [15]; c) finally, ESTROTECT (Rockway Inc., Spring Valley, WI, USA) heat detector patches were used as an aid for riding behavior, according to the company' specifications [8]. Cows were detected by showing overt signs of estrus and palpation, or triggering off the paint from the patches. The gold standard test was the observation of overt signs of estrus.

\subsection{Calf Management}

At the moment of implant withdrawal all cows were started on a regime of restricted suckling allowing calves to suckle for a period of two hours in the morning. Visual contact was possible at all times.

\subsection{Statistical Analysis}

Relative frequencies were calculated using the five groups of cows displaying overt signs of estrus or detected by transrectal palpation after $56 \mathrm{~h}$ from implant withdrawal, together with those not showing signs of estrus. A further calculation was done only with the animals detected in estrus and ovulating either as displaying overt signs or those detected through the patch.

\subsection{Modeling Procedure}

Deterministic models were used to estimate the possible economic advantages of insemination by appointment over detected estrus using the values obtained in the present study.

Associated cost for pregnancy rates after insemination and the results obtained in observational estrus and ovulation were compared. Two strategies of AI were defined: at observed estrus (AIOE), and by appointment (AIA). In the case of AIOE, an estrus detection percentage of $45 \%$ (obtained in the present study) was taken as 
an average scenario. Additionally, two other situations were included, one with a lower estrus detection efficacy (30\%) and the other with a higher rate (67\%), which are the minimum and maximum values obtained in the field study. These values are in agreement with those previously reported [14]. Also, we evaluated a scenario where $96 \%$ of the cows in estrus ovulated, as observed in the present study, and compared this parameter to lower $(85 \%)$ and higher (100\%) ovulation rates after observed estrus.

To model AIA, three scenarios for ovulation rates were considered, average (71\%), low (60\%) and high (80\%) [7]. Finally, for AIA and AIOE, three hypothetical fertility rates were used, average (70\%), low (65\%) and high (75\%), and three costs for commercial semen, $\$ 20.00$, $\$ 30.00$ and $\$ 40.00$ US dollars, fixing the labor cost of IA at $\$ 5.00 / \mathrm{cow}$, and open day at $\$ 3.00 / \mathrm{cow} / \mathrm{day}$. The cost of labor was estimated based on data published in Mexico and Colombia [16]; on the other hand, the cost for days open was an approximation taken from the study published by Vargas et al. [17] for dairy cattle under tropical conditions. It was assumed that cows not pregnant after the first service will have on average a second opportunity after at least 21 additional days. All modeling procedures were established using a baseline of 100 animals.

\section{Results}

Only four out of 63 cows were cycling in the samples taken prior to the synchronization scheme. As shown in Table 1 the global mean of days between calving and CIDR removal was $40.9 \pm 6.8$. On average, $43.4 \%$ of the animals displayed estrous behavior and $22 \%$ were detected as positive by palpation. The use of patches was not consistent, of the 29 cows displaying riding behavior only two of the animals were positive to the heat detector device and three were considered doubtful. Of the 13 animals detected by palpation only one was positive to the heat detector device, and two animals were negative to estrous behavior, but doubtful to the patch.

Figure 1 displays the percentage of cows either showing overt signs of estrus or confirmed positive to estrus by transrectal palpation. There was a significant $(p<0.05)$ difference only between cows in group 1 versus group 5 in relation to the detection of overt signs of estrus.

Figure 2 shows the percentage of animals per group in relation to estrus response and ovulation; differences are not significant $(p>0.05)$. Two features are apparent, the first is the significant number of cows detected in estrus by visual observation that subsequently ovulated, as indicated by progesterone levels above $0.5 \mathrm{ng} / \mathrm{ml}$ ), along with the limited number of errors in detecting animals on the basis of imitation behavior (cows riding other

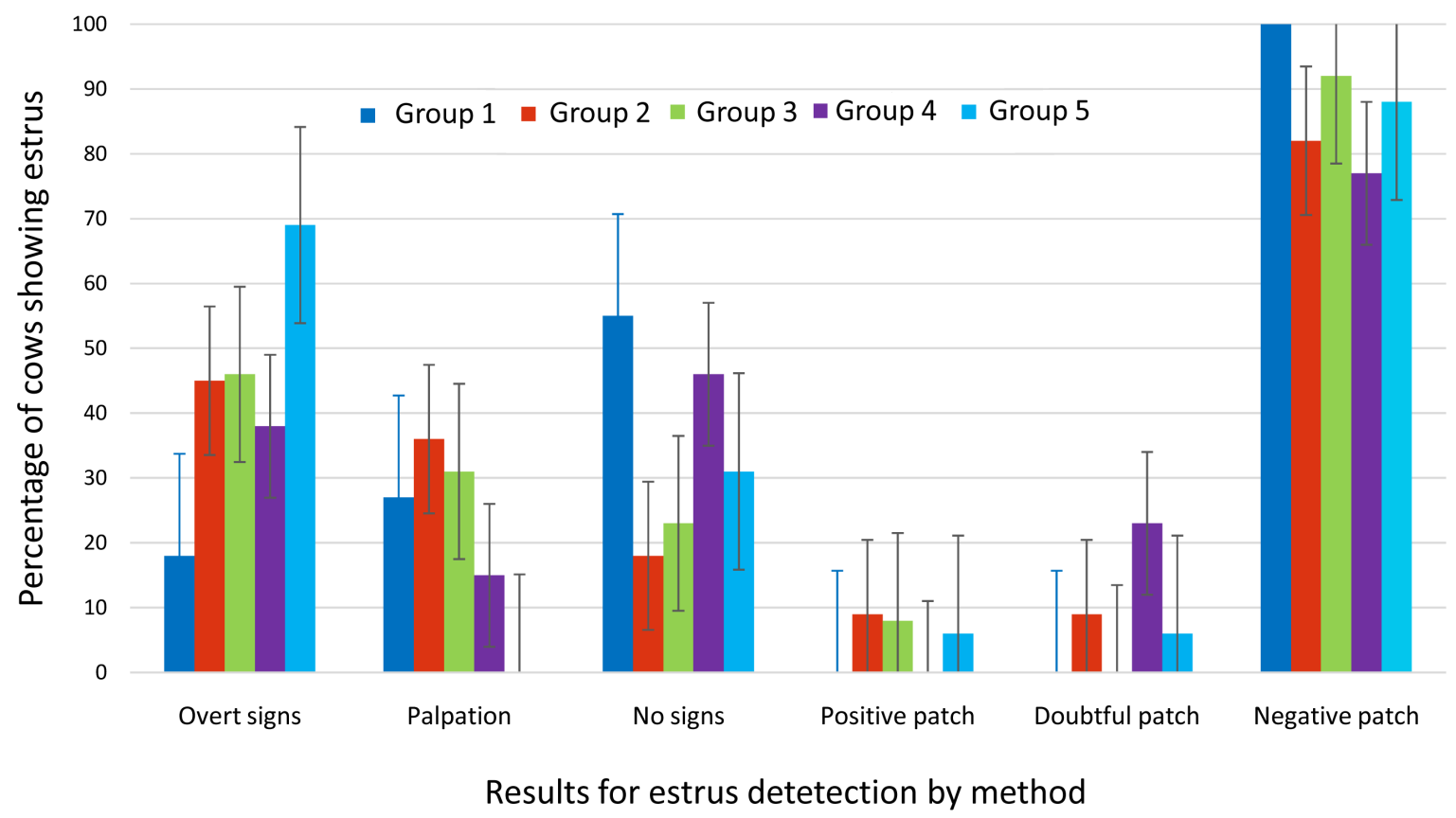

Figure 1. Percentage of cows displaying overt signs of estrus, or detected by transrectal palpation at $56 \mathrm{~h}$ after implant withdrawal or by the use of a patch to evidence mounting behavior. The typical error bar is shown. 


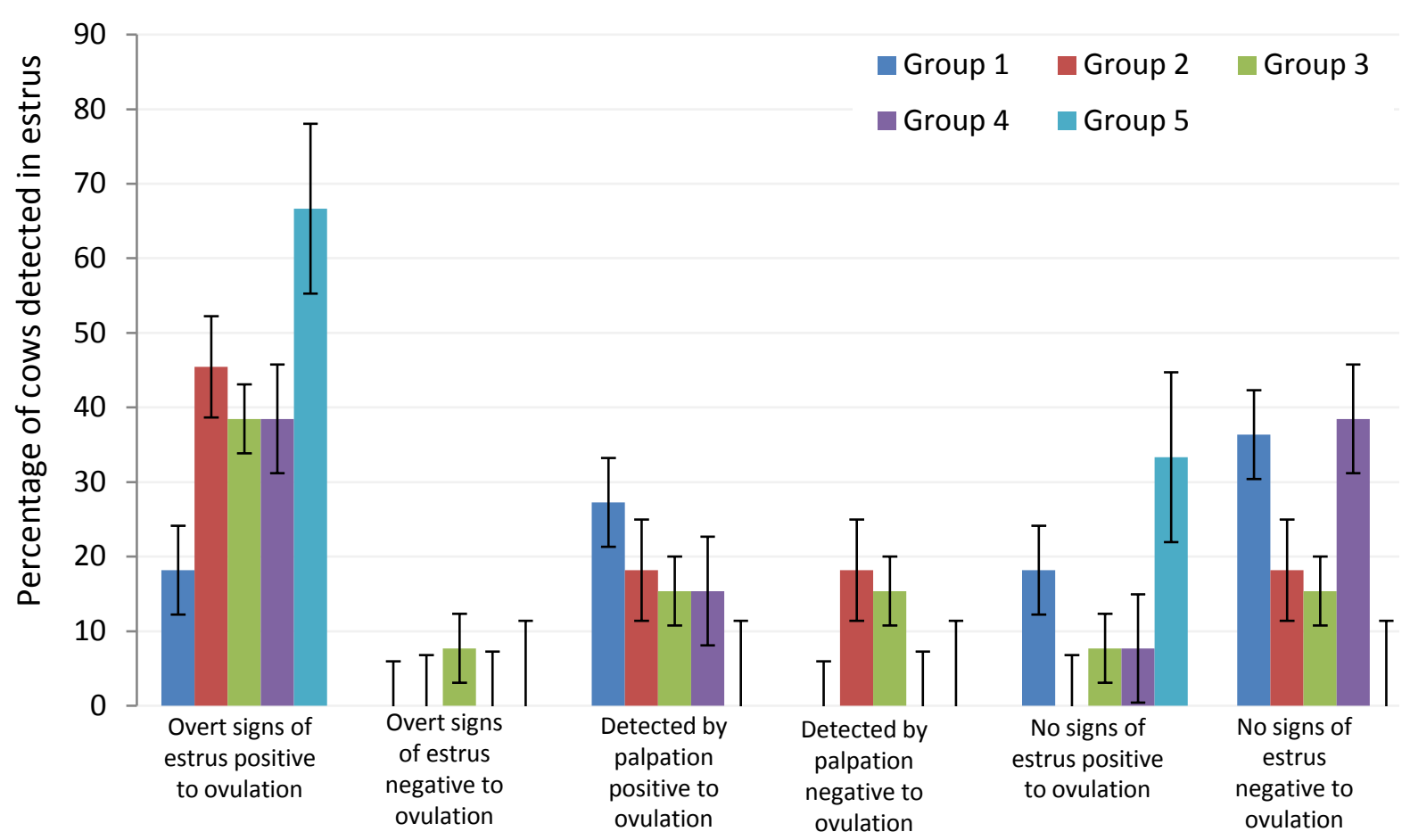

Results of estrus detection by method

Figure 2. Percentage of cows detected in estrus by overt signs, transrectal palpation or positive patches, events followed by an ovulation measured by progesterone concentration above $0.5 \mathrm{ng} / \mathrm{ml}$ in the five treatments.

cows or accepting being ridden). Secondly, the number of cows detected in estrus by palpation that were subsequently tested positive for ovulation (true positives) compared to the number of animals diagnosed in estrus but not ovulating. When calculating the ratio between the animals positive to ovulation through palpation, there was a probability of $30 \%$ error for every cow diagnosed as a true positive.

In reference to the simulation studies, considering different rates of estrus observation, ovulation, fertility and the price of semen, IA by appointment was the better option than IA at observed estrus, using a balance between the expenses for open days less IA at fixed cost. An exception was found in the scenarios with higher reproductive efficiency where the difference between expenses for AIOE and AIA were about $\$ 60.00$ USD (when price for semen was $\$ 20.00$ USD) and $\$ 600.00$ USD (when price for semen rises to $\$ 40.00$ USD). In addition, the difference could reach $\$ 2800.00$ in the scenario with lower reproductive efficiency, when the semen price was set at about $\$ 40.00$ USD (Table 2).

Figure 3 shows the variations between the costs for open days less expenses in the two AI programs. Independent of the price of semen, when reproductive efficiency is high, AIA has higher costs than AIOE. In the case of semen at $\$ 20$ the difference was almost $\$ 300$, at $\$ 30$ it was around $\$ 100$ and for $\$ 40$ it was up to $\$ 600$.

Likewise, using the cost of per pregnant cow after first service as an indicator for comparison in the different scenarios, AIA always resulted more profitable, regardless of the cost of semen. The differences can reach up to $\$ 230.00$ in the worst case scenario of reproductive efficiency, whereas in the cost of semen the difference can increase to $\$ 40.00$ USD. In the average situation, the cost of a pregnancy using AIA is about half that of AIOE independent of the cost of semen (Table 3).

The variation in the cost per pregnant cow, according to the different reproductive efficiencies and the various costs for semen can be observed in Figure 4. Regardless of the price of semen and reproductive efficiency, the cost for a pregnant cow is less in AIA than in AIOE.

\section{Discussion}

The number of cows cycling prior to CIDR removal (average $40.9 \pm 6.8$ ) was only 6\%, this result agrees with 


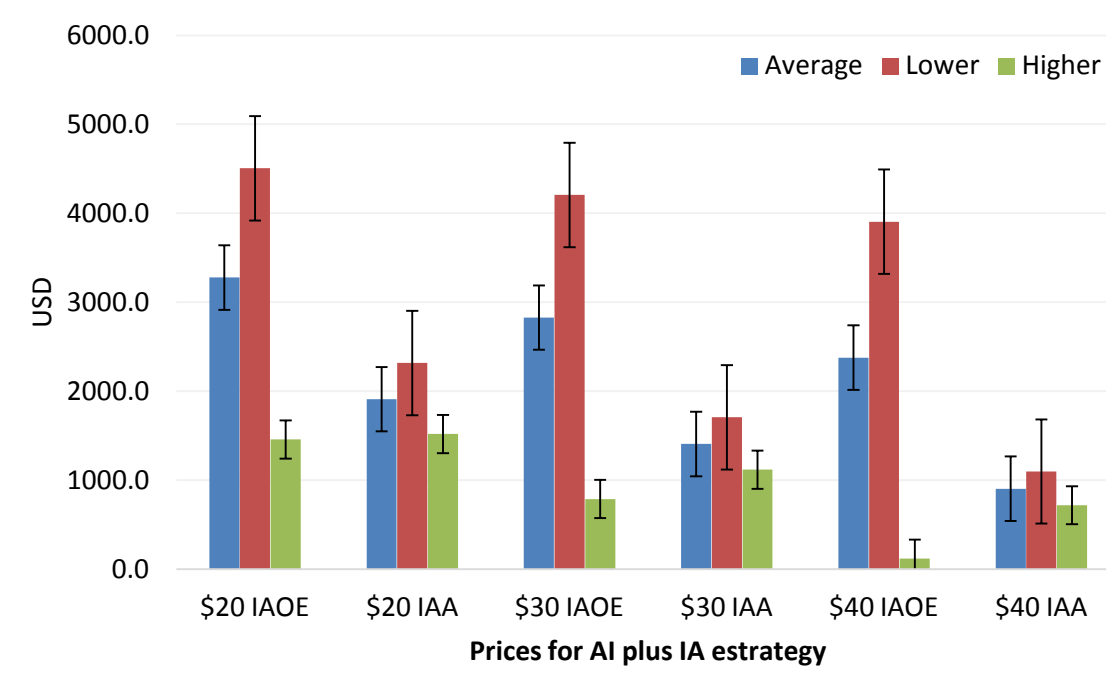

Figure 3. Cost balance per open days-This analysis includes the cost of artificial insemination (AI) at different prices for semen, assuming three scenarios of reproductive efficiency (AIOE = AI at observed estrus; AIA = IA by appointment).

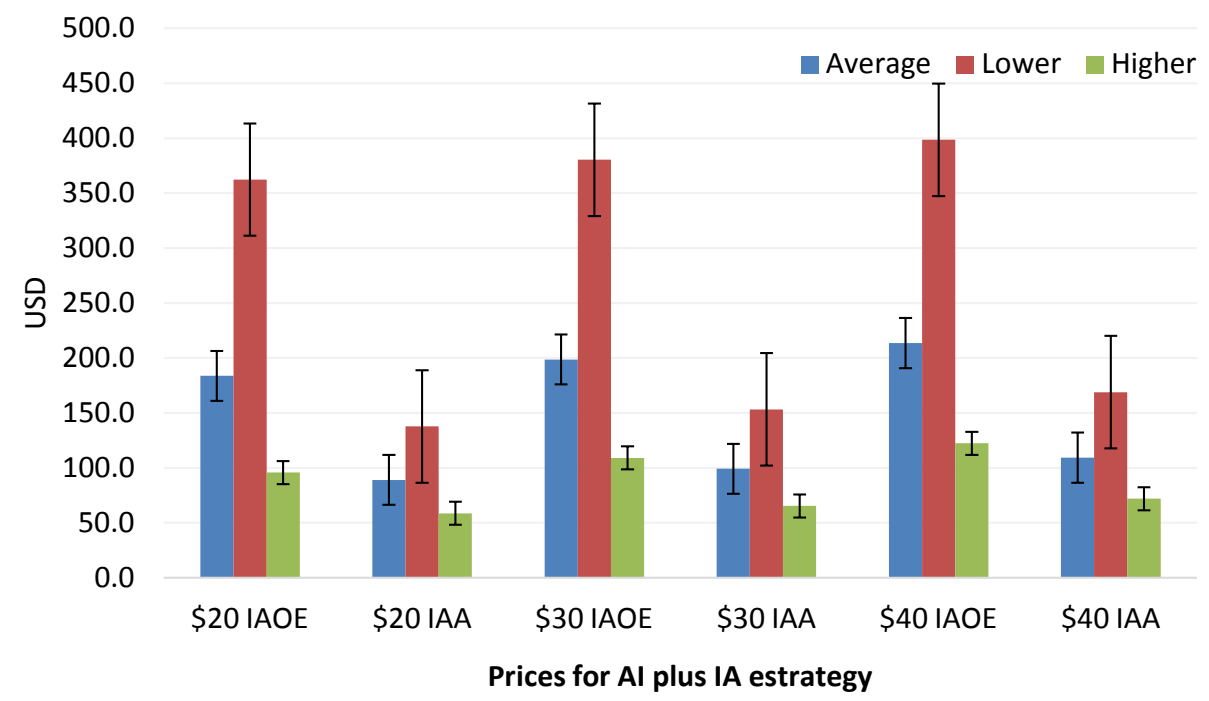

Figure 4. Comparison of cost per pregnant cow in different scenarios and price for semen.

Table 2. Evaluation of costs in relation to open days less IA expenses. This analysis was calculated at different costs for semen for the strategies of AIOE versus AIA, in three scenarios of reproductive efficiency (amounts in USD).

\begin{tabular}{ccccc}
\hline \multirow{2}{*}{ Cost of semen } & IA & \multicolumn{3}{c}{ Scenario Reproductive Efficiency } \\
\cline { 3 - 5 } & AIOE & Average $\mathbf{7 0} \%$ & Lower $\mathbf{6 5 \%}$ & Higher $\mathbf{7 5 \%}$ \\
\hline \multirow{2}{*}{20.0} & AIA & 3278.7 & 4505.8 & 1459.3 \\
& Difference & 1911.4 & 2318.0 & 1520.0 \\
\multirow{2}{*}{30.0} & AIOE & 1367.3 & 2187.8 & -60.8 \\
& AIA & 2828.7 & 4205.8 & 789.3 \\
& Difference & 1408.4 & 1708.0 & -330.8 \\
\multirow{2}{*}{40.0} & AIOE & 1420.3 & 2497.8 & 119.3 \\
& AIA & 2378.7 & 3905.8 & 720.0 \\
\end{tabular}


Table 3. Differences in the cost for a pregnant cow after first IA using different costs for semen. Calculations based on the strategies of AIOE versus AIA, in three scenarios of reproductive efficiency (amounts in USD).

\begin{tabular}{|c|c|c|c|c|}
\hline \multirow{2}{*}{ Cost of semen } & \multirow{2}{*}{ IA } & \multicolumn{3}{|c|}{ Scenario Reproductive Efficiency } \\
\hline & & Average $70 \%$ & Lower $65 \%$ & Higher $75 \%$ \\
\hline \multirow[t]{3}{*}{20.0} & AIOE & 183.7 & 362.3 & 95.7 \\
\hline & AIA & 89.1 & 137.6 & 58.7 \\
\hline & Difference & 94.6 & 224.7 & 37.0 \\
\hline \multirow[t]{3}{*}{30.0} & AIOE & 198.6 & 380.4 & 109.0 \\
\hline & AIA & 99.2 & 153.3 & 65.3 \\
\hline & Difference & 99.4 & 227.2 & 43.7 \\
\hline \multirow[t]{3}{*}{40.0} & AIOE & 213.6 & 398.5 & 122.4 \\
\hline & AIA & 109.3 & 168.9 & 72.0 \\
\hline & Difference & 104.3 & 229.6 & 50.4 \\
\hline
\end{tabular}

the abundant information in the literature indicating late onset of ovarian activity when the cows are kept with their calves at all times [18]. On average, $43.4 \%$ of the animals displayed estrous behavior and $22 \%$ were detected as positive by palpation. The combination of these two procedures has previously proven to be quite efficient to improve detection rates and has been recommended by others [15]. On the contrary, the use of patches was not consistent as only $5 \%$ of the animals were confirmed in estrus with the use of this commercial aid. It is difficult to explain this finding as in previous experiments this method has been quite efficient [8]. We have ruled out the possibility that the patches were too old as they had been kept in a warehouse at all times since their purchase three months prior to use.

As can be observed in Figure 2, the majority of cows detected in estrus by visual observation did in fact ovulate indicating that these animals were likely to become pregnant. Moreover, the limited number of errors in detecting animals by imitation behavior (cows riding other cows or accepting being ridden) suggests above average precision and accuracy in estrus detection in this experiment and compares quite favorably with other studies [14] [19]. This finding could be the consequence of the limited number of animals detected in estrus (about $50 \%$ ) with less than $14 \%$ of animals not detected in estrus and ovulating. This is consistent with data published for Holstein cattle, where detecting cows in estrus solely on the basis of standing to be mounted is seriously questioned [20] [21]. López-Gatius and Camón-Urgwl [15] recommended the use of transrectal palpation as an aid in estrus detection, however, when calculating the ratio between the animals positive to ovulation by palpation, for every cow was diagnosed as a true positive, we found a probability error of 30\% making this technique less than accurate. Fewer than $15 \%$ of animals entering the study and detected positive to estrus by palpation, subsequently ovulated while more than $6 \%$ did not.

Simulation studies in Holstein cows [2] calculating an index of estrus detection efficacy between $85 \%$ and $95 \%$ showed a better economical return if AI was applied at detected estrus as opposed to AI at fixed time. In the case of our study, the values for detected estrus were not above $60 \%$ which was in accord with several studies of cattle raised under tropical conditions [14]. Thus, with the present efficacy in detecting overt signs of estrus, it does not seem economically feasible to recommend this method over insemination by appointment.

All the deterministic economic modeling procedures utilized in the present study point to a definitive advantage of using AI at a predetermined time versus a program based on estrus detection in postpartum cows. This is particularly important in cattle raised under extensive or semi intensive conditions [3] [5]. Basically, even with a reasonable level of accuracy in detecting cows in estrus, the number of animals not displaying overt signs adds to the cost of using AI. This inconvenience, plus the time spent in observing animals, is contrary to the recommendation of using AI at detected estrus [22]. Unless fertility improves [23], AI at a predetermined time is a better recommendation.

A certain bias was present in our fertility calculations following AI as $70 \%$ of animals conceiving is quite a high figure when compared to values reported in the literature [24] [25]. A more realistic figure would be around 
$30 \%$ to $40 \%$. However, even when fertility was calculated at $65 \%$ IA by appointment was less expensive than IA at detected estrus.

\section{References}

[1] De Giordano, J.O., Fricke, P.M. and Cabrera, V.E. (2013) Economics of Resynchronization Strategies Including Chemical Tests to Identify Nonpregnant Cows. Journal of Dairy Science, 96, 949-961. http://dx.doi.org/10.3168/jds.2012-5704

[2] Galvão, K.N., Federico, P., De Vries, A. and Schuenemann, G.M. (2013) Economic Comparison of Reproductive Programs for Dairy Herds Using Estrus Detection, Timed Artificial Insemination, or a Combination. Journal of Dairy Science, 96, 2681-2693. http://dx.doi.org/10.3168/jds.2012-5982

[3] Sá Filho, M.F., Ayres, H., Ferreira, R.M., Marques, M.O., Reis, E.L., Silva, R.C.P., Rodrigues, C.A., Madureira, E.H., Bó, G.A. and Baruselli, P.S. (2010) Equine Chorionic Gonadotropin and Gonadotropin-Releasing Hormone Enhance Fertility in a Norgestomet-Based, Time Artificial Insemination Protocol in Suckled Nelore (Bos indicus) Cows. Theriogenology, 73, 651-658. http://dx.doi.org/10.1016/j.theriogenology.2009.11.004

[4] Baruselli, P.S., Sales, J.N.S., Sala, R.V., Vieira, L.M. and Sá Filho, M.F. (2012) History, Evolution and Perspective of Timed Artificial Insemination Programs in Brazil. Animal Reproduction, 9, 139-152.

[5] Bó, G.A., Baruselli, P.S. and Martinez, M.F. (2003) Pattern and Manipulation of Follicular Development in Bos indicus Cattle. Animal Reproduction Science, 78, 307-326. http://dx.doi.org/10.1016/S0378-4320(03)00097-6

[6] Rodgers, J.C., Bird, S.I., Larson, J.E., Dilorenzo, N., Dahlen, C.R., Diconstanzo, A. and Lamb, G.C. (2012) An Economical Evaluation of Estrous Synchronization and Timed Artificial Insemination in Suckled Beef Cows. Journal of Animal Science, 90, 4055-4062. http://dx.doi.org/10.2527/jas.2011-4836

[7] Díaz, G.S., Galina, C.S., Basurto, C.H. and Ochoa, G.P. (2002) Efecto de la progesterona natural con o sin la adición de benzoato de estradiol sobre la presentación de celo, ovulación y gestación en animales tipo Bos indicus en el trópico mexicano. Archivos de Medicina Veterinaria, 34, 235-244. http://dx.doi.org/10.4067/S0301-732X2002000200009

[8] Pérez-Torres, L., Rubio, I., Corro, M., Cohen, A., Orihuela, A., Galina, C.S. and Pablos, J.L. (2015) A Pre-Synchronization Program at Early Postpartum Might Increase the Chance of Bos indicus Cows Cycling Prior to 50 Days Regardless of the Length of Calf Separation. Journal of Reproduction and Development, 61, 199-203. http://dx.doi.org/10.1262/jrd.2014-114

[9] Alonso-Alanuza, L., Galina-Hidalgo, C.S., Maquivar-Linfoot, M., Romero-Zúñiga, J.J., Molina-Echeverry, I. and Carvajal-Arango, P. (2009) Evaluación de la fertilidad de hembras Bos indicus de acuerdo a la intensidad del celo, manejadas en un programa de inseminación artificial a tiempo fijo en condiciones de trópico. Revista CientíficaFacultad de Ciencias Veterinarias de la Universidad de Zulia, 6, 639-644.

[10] Pullan, N.B. (1978) Condition Scoring of White Fulani Cattle. Tropical Animal Health and Production, 10,110-120. http://dx.doi.org/10.1007/BF02235322

[11] Pulido, A., Zarco, L., Galina, C.S., Murcia, C., Flores, G. and Posadas, E. (1991) Progesterone Metabolism during Storage of Blood Samples from Gyr Cattle: Effects of Anticoagulant, Time and Temperature of Incubation. Theriogenology, 35, 965-975. http://dx.doi.org/10.1016/0093-691X(91)90307-Y

[12] Van Eerdenburg, F.J.C.M., Loeffer, H.S.H. and van Vliet, J.H. (1996) Detection of Oestrus in Dairy Cows: A New Approach to an Old Problem. Veterinary Quarterly, 18, 52-54. http://dx.doi.org/10.1080/01652176.1996.9694615

[13] Maquivar, M., Galina, C.S., Verduzco, A., Galindo, J., Molina, R., Estrada, S. and Mendoza, M.G. (2006) Reproductive Response in Supplemented Heifers in the Humid Tropics of Costa Rica. Animal Reproduction Science, 93, 16-23. http://dx.doi.org/10.1016/j.anireprosci.2005.05.033

[14] Galina, C.S. and Orihuela, A. (2007) The Detection of Estrus in Cattle Raised under Tropical Conditions: What We Know and What We Need to Know. Hormones and Behavior, 52, 32-38. http://dx.doi.org/10.1016/j.yhbeh.2007.03.025

[15] López-Gatius, F. and Camón-Urgel, J. (1991) Confirmation of Estrus Rates by Palpation Per Rectum of Genital Organs in Normal Repeat Dairy Cows. Journal of Veterinary Medicine A, 38, 553-556. http://dx.doi.org/10.1111/j.1439-0442.1991.tb01047.x

[16] Molina, J.J., Molina, I., Jiménez, A., Galina, C.S. and Romero, J.J. (2012) Pharmacological Control of Estrus in Tropical Cattle, an Economical Assessment of Different Synchronization Protocols. Open Journal of Veterinary Medicine, 2, 151-157. http://dx.doi.org/10.4236/ojvm.2012.23024

[17] Vargas, B., Marín, Y. and Romero, J.J. (2012) Comparación bioeconómica de grupos raciales Holstein, Jersey y Holstein x Jersey en Costa Rica. Agronomía Mesoamericana, 23, 329-342. http://dx.doi.org/10.15517/am.v23i2.6533

[18] McNeilly, A.S. (2006) Suckling and the Control of Gonadotropin Secretion. In: Neill, J.D., Ed., Knobil and Neill's 
Physiology of Reproduction, 3rd Edition, Elsevier Academic Press, St. Louis, 2511-2536. http://dx.doi.org/10.1016/B978-012515400-0/50051-8

[19] Woldu, T., Giorgis, Y.T. and Haile, A. (2011) Factors Affecting Conception Rate in Artificially Inseminated Cattle under Farmers Condition in Ethiopia. Journal of Cell and Animal Biology, 5, 334-338.

http://dx.doi.org/10.5897/JCAB11.067

[20] Lyimo, Z.C., Nielen, M., Ouweltjes, W., Kruip, T.A.M. and van Eerdenburg, F.J.C.M. (2000) Relationships among Estradiol, Cortisol and Intensity of Estrus Behavior in Dairy Cattle. Theriogenology, 53, 1783-1795. http://dx.doi.org/10.1016/S0093-691X(00)00314-9

[21] Kerbrat, S. and Disenhaus, C. (2004) A Proposition for an Updated Behavioural Characterization of the Oestrus Period in Dairy Cows. Applied Animal Behaviour Science, 87, 223-238. http://dx.doi.org/10.1016/j.applanim.2003.12.001

[22] Malik, A., Wahid, H., Rosnina, Y., Kasim, A. and Sabri, M. (2012) Effects of Timed Artificial Insemination Following Estrus Synchronization in Postpartum Beef Cattle. Open Veterinary Journal, 2, 1-5.

[23] Ghosh, T., Ashit, K.P., Anup, K.T., Golam, S.A. and Farisa, Y.B. (2012) Use of Two Estrus Synchronization Protocols and Their Success on Pregnancy in Zebu and Crossbred Heifers at Char Areas of Bangladesh. Journal of Embryo Transfer, 27, 223-228. http://dx.doi.org/10.12750/JET.2012.27.4.223

[24] Galina, C.S. and Arthur, G.H. (1989) Review of Cattle Reproduction in the Tropics Part 1. Puberty and Age at First Calving. Animal Breeding Abstracts, 57, 583-590.

[25] Ramirez-Iglesias, L.N., Roman Bravo, R.M., Díaz de Ramirez, A. and Torres, L.J. (2014) Fertility in Gyr Cows (Bos indicus) with Fixed Time Artificial Insemination and Visual Estrus Detection Using a Classification Table. Journal of Veterinary Medicine, 2014, Article ID: 404363. http://dx.doi.org/10.1155/2014/404363 